\title{
BODY DIFFICULTIES IN JUNIOR RHYTHMIC GYMNASTICS ACCORDING TO THE FIG CODE OF POINTS
}

\author{
Ștefania CHIRIAC ${ }^{1 *}$, Silvia TEODORESCU ${ }^{1}$, Aura BOTA ${ }^{1}$ \\ ${ }^{1}$ National University of Physical Education and Sport, Faculty of Physical Education and Sport, Bucharest, Romania \\ *Corresponding author: stefania.chiriac24@gmail.com
}

DOI: 10.35189/iphm.icpesk.2019.8

\begin{abstract}
This study aimed at analysing the 2018 European Championships from the perspective of rhythmic gymnastics routines at junior level, based on the criterion of difficulty elements and execution times, taking into consideration the current FIG Code of Points. Secondly, we aimed at comparing the finalists' routines with those of the Romanian gymnasts according to the same criterion. Data were collected using the video analysis of 39 routines performed during the qualifications and finals for four apparatus: hoop, ball, clubs and ribbon. The investigated gymnasts were aged between 13 and 15 years. Descriptive statistics were used for the following cues: number of difficulty elements divided by body and apparatus difficulties and their contribution to the maximal number allowed, along with the scores and execution times for all difficulty elements performed in the routines. Data reveal several interesting aspects related to: the ratio between the number and value of the difficulty elements determined by the gymnasts' capabilities and their prevalence in the four apparatus events; the implications of the Code of Points difficulty provisions on the variety of compositions; the relevance of the execution times for the possibility of adding more difficulty elements; the differential notes of the Romanian gymnasts' compositions and their weight in the final score. The Code of Points puts an emphasis on the apparatus handling variety, with implications on the uniqueness and spectacular effects on the judges and public.
\end{abstract}

Keywords: rhythmic gymnastics, Code of Points, difficulty elements.

\section{Introduction}

As an Olympic sport discipline, rhythmic gymnastics updates on a regular basis its Code of Points in order to bring clarification of the judging criteria, enhance objectivity in evaluation, diminish injury risks related to performing some technical elements and also improve the sports quality (Manos \& Popescu, 2014).

Each new configuration of the Code of Points in all gymnastic sports influences its technical content in terms of refining the execution accuracy and bringing more spectacular routines (Bota, Urzeală, \& Mezei, 2012).

Recent references emphasise several topics related to analysing the technical content of elite rhythmic gymnastics by correlating the difficulty elements and their prevalence in the final score (Leandro, Avila-Carvalho, Sierra-Palmeiro, \& Bobo-Arce, 2016). Body difficulty (BD) elements were analysed according to the composition requirements for determining whether there were significant differences between gymnasts.

Specialists like Macovei and Buțu (2018, p. 20) or Avila-Carvalho, da Luz Palomero, Klentrou and Lebre (2012), considering the previous Code of Points (2009-2012), acknowledge that, in that period, it was a limited variety of difficulty elements, with consequences on the routine composition, which was considered boring and lacking artistic value. Thus, it is essential to increase the interaction between gymnasts and apparatus and to increase the level of difficulty elements, with positive effects on the routine composition (Lebre, 2011).

Similar studies (Leandro, 2018) compared the evolution of the apparatus difficulty in two Olympic cycles (2013-2016 and 2017-2020), showing a significant increase of these criterion from one cycle to the other due to the limitless number of elements possibly included in the routines.

Ferreirinha, Carvalho, Corte-Real and Silva (2011) claim that all training models depend on the deep knowledge of the Code of Points, so that the routine composition takes into consideration all the content details.

In the long run, analysing the successive Code of Points brings insights into the development trends in rhythmic gymnastics, considering that, based on the technical contents, each gymnast can create a specific style, an original configuration of the routine and a perfect presentation (Wang, Lu, \& Sun, 2013).

Generally speaking, the scientific background of this topic brings to surface the importance of thoroughly analysing the Code of Points for the following reasons (Liviotti \& Hokelmann, 2012):

- adjusting the coaching process;

- creating performance profiles for the gymnast;

- ranking performances;

- creating databases to identify the most important performance indicators and develop trends in rhythmic gymnastics. 


\section{Problem statement}

According to the current FIG Code of Points (2017-2020), the requirements for difficulty are shown in Table 1.

Table 1. Difficulty requirements according to the Code of Points 2017-2020

\begin{tabular}{lcccc}
\hline $\begin{array}{c}\text { Difficulty Components } \\
\text { connected with apparatus } \\
\text { technical elements }\end{array}$ & Body Difficulty & $\begin{array}{c}\text { Dance Steps } \\
\text { Combination }\end{array}$ & $\begin{array}{c}\text { Dynamic } \\
\text { Elements with } \\
\text { Rotation }\end{array}$ & $\begin{array}{c}\text { Apparatus } \\
\text { Difficulty }\end{array}$ \\
\hline Symbol & BD & S & R & AD \\
& $\begin{array}{c}\text { Minimum 3 } \\
\text { 7 BD highest count } \\
\text { Bump/Leaps - Min. 1 }\end{array}$ & & Minimum 1 & Min. no./ \\
& Balances - Min. 1 & & & Max. no. \\
& Rotations - Min. 1 & & & \\
\hline
\end{tabular}

Adding up all these components will result in the difficulty score including possible penalties.

These technical aspects are to be incorporated in the training process of the Romanian junior team by objectively analysing the latest trends in the routines of most valuable gymnasts. The technical staff should also be interested in identifying the differential notes between the best junior gymnasts' difficulty scores and those of the Romanian gymnasts, so that emphasis is placed on proper technical preparation associated with adequate physical preparation.

Given the requirements of the Code of Points and the gymnasts' capabilities, coaches have to be more realistic in how they choose the technical elements, the number of elements and how they meet the criteria of the judging system so that we can talk about rationalising the technical content according to each gymnast's complex profile.

\section{Research questions}

How does the execution time of difficulty elements influence the difficulty score?

Are there significant differences between the number of difficulty elements performed by the most valuable gymnasts and the Romanian gymnasts?

\section{Aim of the study}

This study aimed at analysing the 2018 European Championships from the perspective of rhythmic gymnastics routines at junior level, based on the criterion of difficulty elements and execution times, taking into consideration the current FIG Code of Points. Secondly, we aimed at comparing the finalists' routines with those of the Romanian gymnasts according to the same criterion.

\section{Material and Methods}

\section{Research subjects and location}

The gymnasts analysed were aged between 13-15 years at the time of their participation in the $34^{\text {th }}$ edition of the 2018 European Rhythmic Gymnastics Championships, which took place in Guadalajara.

In total, 73 gymnasts were included in the qualification competition and 32 became finalists. Their routines where analysed in this study together with other seven routines performed by the Romanian gymnasts in the qualification round.

\section{Research techniques used}

In this descriptive, comparative study, the main research methods used were: observation, video analysis, statistical method and graphical representation. The recorded videos were played frame by frame and allowed replay in order to perform a thorough judging process.

During active observation through video analysis, we also measured the execution time of difficulty elements for each routine performed in the final competition and in the qualification round for the Romanian gymnasts.

Data were collected using the video analysis of 39 routines performed during the qualifications and finals for four apparatus: hoop, ball, clubs and ribbon. 
Taking into account the final scores for each routine (provided by the UEG competition website), we (re)evaluated each routine (given our competences as certified second-category judges) in order to determine the sub-scores for each difficulty component, as well as the execution times for each difficulty element included in these routines.

Descriptive statistics were used for the following cues: number of difficulty elements divided by body and apparatus difficulties and their contribution to the maximal number allowed, along with the scores and execution times for all difficulty elements performed in the routines.

This study was carried out in two phases:

- drawing up the descriptive charts for the 39 routines, emphasising the number of difficulty elements, the types of elements (jumps, balances, rotations and apparatus handling techniques) and their prevalence over the total number;

- measuring the execution time for each technical difficulty in all 39 routines along with their values, according to the FIG Code of Points (through the judging process).

\section{Results and Discussion}

During the video analysis of the routines, we drew up 39 descriptive charts for each apparatus, as shown in Table 2, including the difficulty elements and their values according to the FIG Code of Points for a hoop routine performed by the winner of this final.

Table 2. Distribution of difficulty elements throughout a hoop routine

\begin{tabular}{|c|c|c|c|c|c|c|c|c|c|}
\hline Butterfly & $\begin{array}{l}\text { Dance Steps } \\
\text { Combination }\end{array}$ & $\mathrm{AD}$ & $\begin{array}{c}\text { Jeté en } \\
\text { tournant } \\
\text { Stag leap } \\
\text { with back } \\
\text { bend }\end{array}$ & DER & $\mathrm{AD}$ & $\begin{array}{l}\text { Penché: body } \\
\text { bent at the } \\
\text { horizontal, } \\
\text { leg in back } \\
\text { split, rotation } \\
\text { on flat foot }\end{array}$ & DER & $\begin{array}{l}\text { Dance Steps } \\
\text { Combination }\end{array}$ & $\mathrm{AD}$ \\
\hline$\frac{1}{\bowtie}$ & $\mathrm{S}$ & $\begin{array}{l}\rightarrow(0 \\
\neq)\end{array}$ & ${ }_{0}^{\circ}$ & $\begin{array}{c}\phi \\
\text { R2 } z \\
\neq \varnothing x\end{array}$ & $\mathrm{O}_{(\neq}$ & 离 & 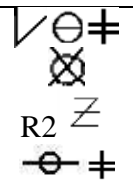 & $\mathrm{S}$ & $\begin{array}{l}\ldots 00 \\
(\neq \\
d\end{array}$ \\
\hline 0.50 & 0.30 & 0.20 & 0.50 & 0.60 & 0.20 & 0.70 & 0.90 & 0.30 & 0.30 \\
\hline $\mathrm{AD}$ & $\begin{array}{l}\text { Balance, } \\
\text { split with } \\
\text { trunk } \\
\text { backward } \\
\text { below } \\
\text { horizontal }\end{array}$ & $\begin{array}{c}\text { Jeté en } \\
\text { tournant } \\
\text { Split } \\
\text { leap with } \\
\text { back } \\
\text { bend }\end{array}$ & $\begin{array}{c}\text { Jeté en } \\
\text { tournant } \\
\text { Split leap } \\
\text { with back } \\
\text { bend }\end{array}$ & DER & $\begin{array}{c}\text { Ring } \\
\text { pivot } \\
\text { with } \\
\text { support }\end{array}$ & $\begin{array}{l}\text { Dance Steps } \\
\text { Combination }\end{array}$ & $\mathrm{AD}$ & $\mathrm{AD}$ & $\mathrm{AD}$ \\
\hline$\left.O_{(\neq} \neq x\right)$ & 缕 & $0^{\circ}$ & $0^{\circ}$ & $\begin{array}{l}\phi \\
\mathrm{R} 2 z \\
\not \neq \neq\end{array}$ & 4 & $\mathrm{~S}$ & $\overrightarrow{x^{2}}(\neq$ & $\downarrow$ (キ邓) & $\begin{array}{l}\overrightarrow{(\neq} \\
\not \infty)\end{array}$ \\
\hline 0.20 & 0.50 & 0.60 & 0.60 & 0.60 & 0.50 & 0.30 & 0.20 & 0.40 & 0.20 \\
\hline DER & $\mathrm{AD}$ & & & & & & & & \\
\hline $\begin{array}{l}\not \\
\mathrm{R} 3 z \neq \\
x^{\prime}\end{array}$ & $\underset{(\mathrm{BD})}{\downarrow \bullet}$ & & & & & & & & \\
\hline 0.80 & 0.40 & & & & & & & & \\
\hline
\end{tabular}

By means of the video analysis, an interesting aspect has been revealed: the FIG Code of Points 2017-2020 includes 87 types of jumps, 63 types of balances and 43 types of rotations. Still, out of the total of 193 difficulty elements, only a small part - 31 is actually performed by the gymnasts (Figure 1). This might imply either:

- limited technical skills in terms of variety of elements within each group;

- gymnasts' preference for those difficulties that are better scored in the Code of Points;

- compositions including technical difficulties that can be performed with high execution speed. 


\section{Frequency of body difficulties throughout all routines}

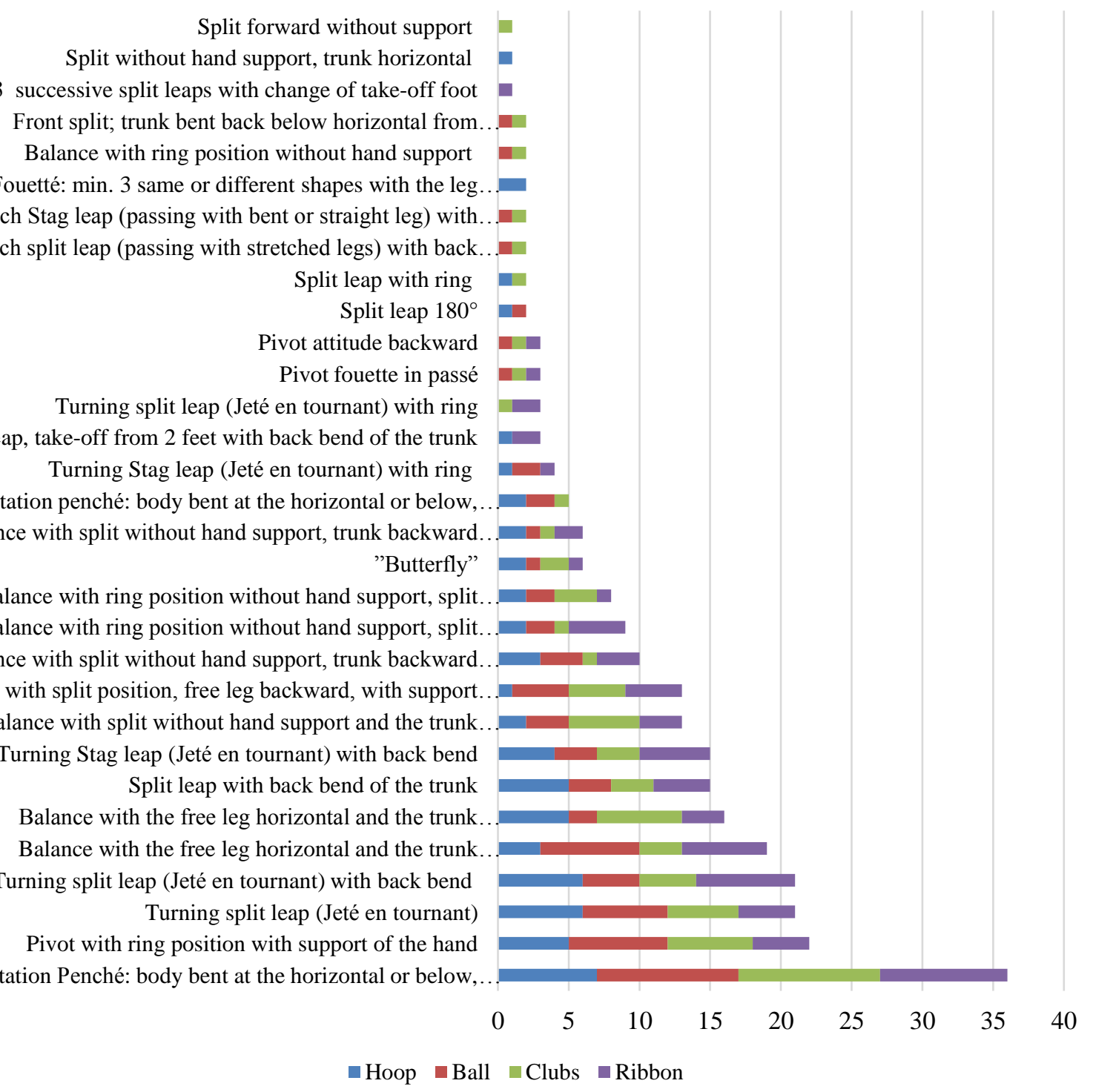

Figure 1. Extensive list of body difficulties performed in all routines analysed

The descriptive charts of the routines emphasised that, out of a total of 344 apparatus difficulties, 125 were based on small throws, 55 being performed during the clubs routines, which represents $36.33 \%$ of the total. These elements were followed by catches from a large throw, with 52 iterations $-15.11 \%$ ( 23 in the hoop routines and 18 in the ball routines), and the roll over minimum two large body segments, with 36 iterations $-10.46 \%$ (most of them, 19, performed in the ball routines) (Figure 2). 


\section{Frequency of apparatus difficulties throughout all routines}

Snakes (4-5 waves), tight and the same height in the air...I

$$
\text { Rotations of the hoop around its axis I }
$$

Passing through or over the pattern of the ribbon or hoop

$$
\text { Echappe }
$$

Other apparatus handling

Rotation ofthe hoop

Large or medium throw

Spirals (4-5 loops), tight and the same height in the air.

Unstable balance of apparatus on a part of the body

Transmission of the apparatus around any part of the.

Bounces

Small throws of 2 Clubs together simultaneously.

Roll of the appatus over min. 2 large body segments

Catch of the apparatus

Small throws/catches

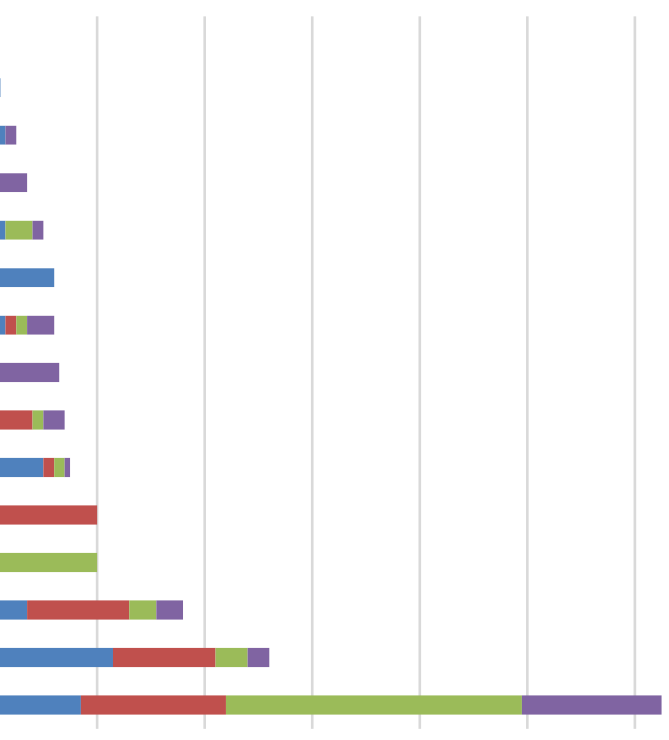

$\begin{array}{rrrrrrrr} & 0 & 20 & 40 & 60 & 80 & 100 & 120 \\ \square \text { Hoop } \square \text { Ball } & \square \text { Clubs } & \square \text { Ribbon }\end{array}$

Figure 2. Extensive list of apparatus difficulties performed in all routines analysed

Concerning the dance steps combinations, the FIG Code of Points requires minimum two for the junior category, each lasting at least 8 seconds. Our quantitative analysis identified, for all 39 routines, 83 combinations, most of them performed during the ribbon routines (27), 19 performed in the hoop and clubs routines and 18 being included in the ball compositions (Figure 3).

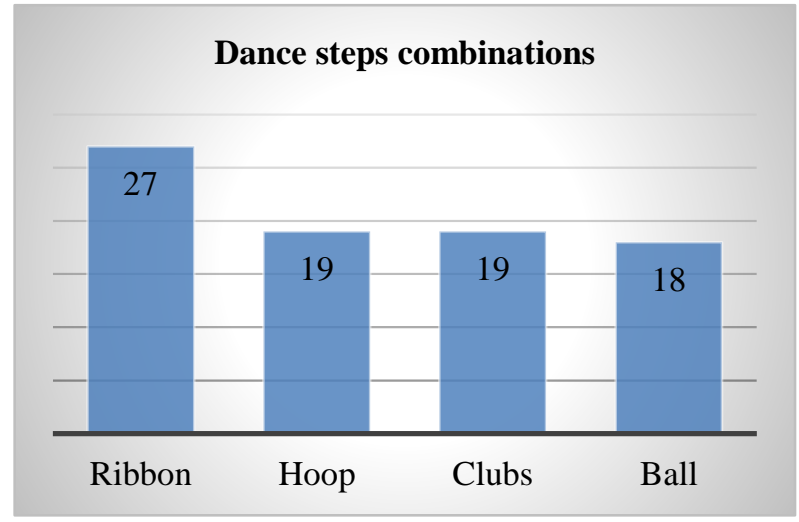

Figure 3. Number of Dance steps combinations

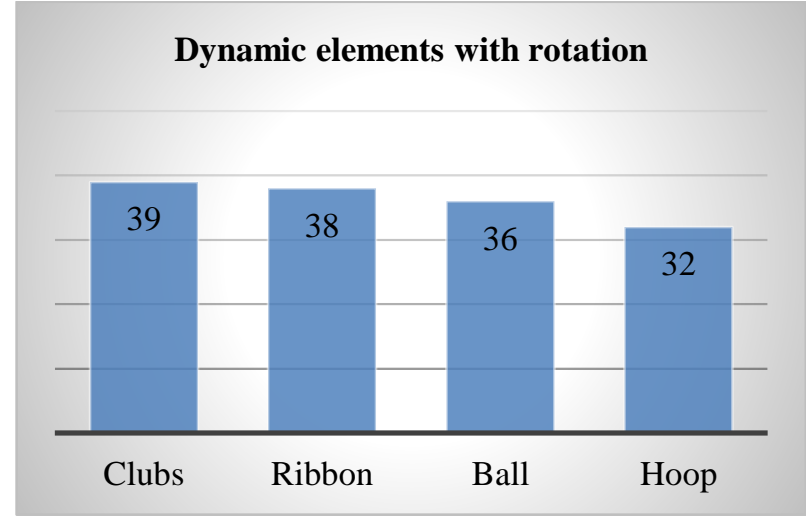

Figure 4. Number of Dynamic elements with rotation

Another technical requirement is represented by the dynamic elements with rotation. Unlike the apparatus difficulties, which are not limited as number or type, these elements can be performed 1 to 4 times in a routine with different types of rotations. Figure 4 depicts the total number of dynamic elements with rotation (145) performed in each apparatus routine (39 in the clubs, 38 in the ribbon, 36 in the ball and 32 in the hoop routines), representing $17 \%$ of the total number of difficulties.

From a qualitative perspective, the dance steps combinations were more numerous and varied in the ribbon routines due to a more limited possibility to perform apparatus difficulties, while in the other apparatus routines, this component is less exploited because there are more options to use the other components of the difficulty criterion. 
In order to identify objective cues that can describe a valuable routine in rhythmic gymnastics, we chose to analyse the execution times for each difficulty element and thus find possible links with the total difficulty score.

Table 3 shows the comparative findings, in terms of execution times, for the finalists in the hoop apparatus, including a Romanian gymnast who performed only in the qualifications.

Table 3. Execution times of difficulty elements related to the difficulty score

\begin{tabular}{lcccc}
\hline & & \multicolumn{2}{c}{ Hoop } & \\
\cline { 2 - 3 } No. & Name initials and country & Total time & Total value & Total number of elements \\
\hline 1 & PK - UKR & $1: 21: 37$ & 9.800 & 23 \\
2 & OR - ESP & $1: 18: 78$ & 7.900 & 21 \\
3 & TT - ITA & $1: 18: 21$ & 9.300 & 24 \\
4 & JNC - FRA & $1: 18: 06$ & 7.700 & 17 \\
5 & VT - BUL & $1: 17: 90$ & 9.100 & 22 \\
6 & SD - ROU & $1: 17: 66$ & 8.400 & 19 \\
7 & SP - RUS & $1: 16: 05$ & 9.800 & 22 \\
8 & AL - ROU & $1: 12: 81$ & 9.000 & 22 \\
9 & NS - AZE & $1: 07: 35$ & 8.200 & 23 \\
\hline
\end{tabular}

Data in Table 3 can be interpreted in multiple perspectives. We notice that the first gymnast had the greatest cumulated execution time for the 23 elements of difficulty, totalising a difficulty score of 9.80 points. The winner of this final (marked in colour) spent less time in performing the 22 elements, cumulating the same difficulty score. The time difference between these gymnasts allowed the winner to better fulfil the artistic criteria (connections between elements, arm movements, stylised connection steps, body waves, etc.), which made the difference in the final score.

Comparing the Romanian gymnast with the winner of the final, several observations can be made:

- the execution time is less than the Russian gymnast's, although the number of difficulty elements is similar;

- the total difficulty score is 0.80 points lower than the winner's, because of greater values of the body difficulties for the Russian gymnast and an extra dance steps combination included in the routine;

- the 3 dynamic elements with rotation were awarded 1.90 points, while for the winner, the 4 similar elements were awarded 2.70 points.

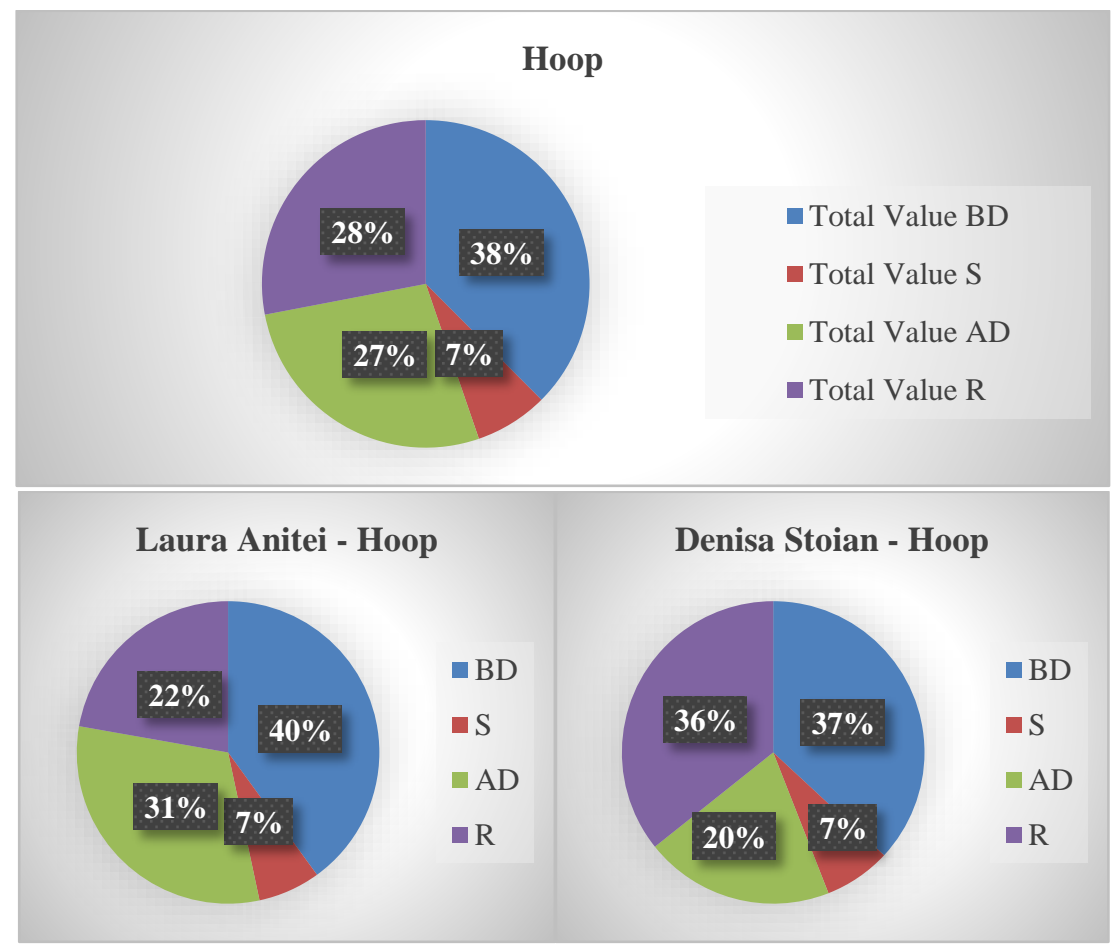


Figure 5. Prevalence of the component-difficulty scores within the total difficulty score

The analysis carried out for each apparatus lead us to identify the prevalence of each component within the total difficulty score. Figure 5 shows these data for the hoop routine, including a comparison between the Romanian gymnasts' scores and the average ones.

Regarding the body difficulties (BD), Romanian gymnasts are close to the average score of $38 \%$ from the final difficulty score. One can notice that this component is the most important within the final score. In terms of dance steps combinations (S), we identified similar percentages compared to the average value (7\%). As to the apparatus difficulties (AD), the average score is $27 \%$, which is quite different from the scores of our gymnasts; one of them is more skilful in handling the apparatus (31\% of the final difficulty score), while the other relies more on the other components ( $20 \%$ of the final difficulty score). As for the dynamic elements with rotation $(\mathrm{R})$, the average value of $28 \%$ is clearly exceeded by one of our gymnasts, whose score for the 4 elements is $36 \%$ from the total difficulty score. The other gymnast has a percentage of $20 \%$, as she had only 3 such elements included in the routine.

\section{Conclusion}

The analysis carried out for each apparatus has led us to identify the prevalence of each component within the total difficulty score: body difficulties are the most prevalent, followed by apparatus difficulty, dynamic elements with rotation and dance steps combination.

The routines analysed in this study have revealed that junior elite gymnasts tend to perform the same types of technical body difficulties in their routines, which leads to a certain predictability of the composition design or even monotonous routines.

Current rhythmic gymnastics requires a strategic vision in terms of routine composition. Time characteristics of the difficulty element execution have to be incorporated into this vision, and the relationships between the gymnasts' individual characteristics and the composition design have to be determined.

Generally, we can assume that high scores in difficulty can be achieved by shortening the preparation time of the elements, which could enable the gymnasts to perform more difficulties.

\section{References}

Avila-Carvalho, L., da Luz Palomero, M., Klentrou, P., \& Lebre, E. (2012). Analysis of the technical content of elite rhythmic gymnastics group routines. The Open Sports Sciences Journal, 5(1), 146-153. Retrieved from https://pdfs.semanticscholar.org/8dfc/f08b576ff52754c67a7a24354f2dc8c6ef9a.pdf

Bota, A., Urzeală, C., \& Mezei, M. (2012). Correlative aspects regarding the functional exertion and the technical difficulty elements in high performance aerobic gymnastics. Ovidius University Annals, Series Physical Education and Sport/ Science, Movement and Health, XII(2), 120-125. Retrieved from http://www.analefefs.ro/anale-fefs/2012/issue-2/pe-autori/2.pdf

Ferreirinha, J., Carvalho, J., Corte-Real, C., \& Silva, A. J. (2011). Evolucao do valor Real de dificuldade dos exercicios de elite nos ultimos ciclos olimpicos [Evolution of the real difficulty value of elite exercises in the last Olympic cycles]. In C. Peixoto, P. Barata, \& L. Moreira (Eds.), Da pratica a ciencia (pp. 71-78). Lisboa. Federação de Ginástica. $\quad$ Retrieved from https://www.researchgate.net/publication/259179044_Evolucao_do_Valor_Real_de_Dificuldade_dos_Exercici os_de_Paralelas_Assimetricas_de_Ginastas_de_Elite_nos_ultimos_5_Ciclos_Olimpicos

Leandro, C. (2018). Apparatus difficulty in rhythmic gymnastics routines - Comparison between 2 Olympic cycles. Science of Gymnastics Journal, 10(3), 413-419. Retrieved from file://C:/Users/Admin/Documents/Downloads/SCGYM_10_3_2018_article_6.pdf

Leandro, C., Avila-Carvalho, L., Sierra-Palmeiro, E., \& Bobo-Arce, M. (2016). Technical content of elite rhythmic gymnastics. Science of Gymnastics Journal, 8(1), 85-96. Retrieved from https://www.researchgate.net/publication/298072382_Technical_content_of_elite_rhythmic_gymnastics

Lebre, E. (2011). Technical principles for the new framework. Crossroads to the future. Switzerland: International Federation of Gymnastics Scientific Commission.

Liviotti, G., \& Hokelmann, A. (2012). Which quantifiable performance parameter(s) determined the medals winners at the World Championship 2011 in rhythmic gymnastics group competition? In Proceedings of VI 
International Scientific Conference of Students and Young Scientists "Modern University Sport Science” (pp. 43-46). Moscow: Russian State University of Physical Education, Sport, Youth and Tourism. Retrieved from http://docplayer.net/119708086-Proceedings-of-vi-international-scientific-conference-of-students-and-youngscientists-modern-university-sport-science.html

Macovei, S., \& Buțu, I. (2018). Tehnica de mânuire a obiectelor în antrenamentul de gimnastică ritmică [The apparatus handling technique in rhythmic gymnastics training]. Craiova: Universitaria.

Manos, M., \& Popescu, L. (2014). The impact induced by the 2009-2012 FIG Code of Points on artistic compositions in rhythmic gymnastics group events. Procedia - Social and Behavioral Sciences, 117, 300-306. https://doi.org/10.1016/j.sbspro.2014.02.217

Wang, M., Lu, M., \& Sun, X. (2013). Structural characteristics of the rhythmic gymnastics difficulty system examined from the perspective of the new rules. Journal of Physical Education / Tiyu Xuekan, 5(20), 117-212. 